\title{
Evaluation of Two Biodegradable Polymeric Systems as Substrates for Bone Tissue Engineering
}

\author{
S.C. MENDES, Ph.D., ${ }^{1,2}$ J. BEZEMER, Ph.D., ${ }^{1}$ M.B. CLAASE, M.Sc., ${ }^{2}$ D.W. GRIJPMA, Ph.D., ${ }^{2}$ \\ G. BELLIA, Ph.D., ${ }^{3}$ F. DEGLI-INNOCENTI, Ph.D., ${ }^{3}$ R.L. REIS, Ph.D., ${ }^{4}$ K. DE GROOT, Ph.D., 1 \\ C.A. VAN BLITTERSWIJK, Ph.D., ${ }^{1,2}$ and J.D. DE BRUIJN, Ph.D. ${ }^{1}$
}

\begin{abstract}
The aim of this study was to evaluate two biodegradable polymeric systems as scaffolds for bone tissue engineering. Rat bone marrow cells were seeded and cultured for 1 week on two biodegradable porous polymeric systems, one composed of poly(ethylene glycol)-terephthalate/poly(butylene terephthalate) (PEGT/PBT) and the other composed of cornstarch blended with poly $(\varepsilon$-caprolactone) (SPCL). Porous hydroxyapatite granules were used as controls. The ability of cells to proliferate and form extracellular matrix on these scaffolds was assessed by a DNA quantification assay and by scanning electron microscopy examination; their osteogenic differentiation was screened by the expression of alkaline phosphatase. In addition, the in vivo osteogenic potential of the engineered constructs was evaluated through ectopic implantation in a nude mouse model. Results revealed that cells were able to proliferate, differentiate, and form extracellular matrix on all materials tested. Moreover, all constructs induced abundant formation of bone and bone marrow after 4 weeks of implantation. The extent of osteogenesis ( $\sim 30 \%$ of void volume) was similar in all types of implants. However, the amount of bone marrow and the degree of bone contact were higher on HA scaffolds, indicating that the polymers still need to be modulated for higher osteoconductive capacity. Nevertheless, the findings suggest that both PEGT/PBT and SPCL systems are excellent candidates to be used as scaffolds for a cell therapy approach in the treatment of bone defects.
\end{abstract}

\section{INTRODUCTION}

I $\mathrm{N}$ SEVERAL Clinical SituATions, a large amount of bone tissue is required to regenerate osseous defects caused by trauma, tumor, and abnormal skeletal development. The graft materials used to heal such problems depend on the type and size of the defect but, essentially, include autologous and allogeneic bone, as well as synthetic biomaterials such as metals, ceramics, and polymers. Despite the wide range of available grafting materials, the development of novel and efficient therapies is required because of the serious limitations presented by the current bone grafts. Although autologous bone is seen as the "gold standard" to treat bone defects, because it is the patient's own and osteoinductive, it also implies an invasive surgical procedure that is associated with postoperative pain and donor site morbidity. In addition, there are limits to the amount of bone that can be collected and the harvested bone must be manually shaped to fit the defect. ${ }^{1}$ Allogeneic bone can solve some of these limitations, such as postoperative patient discomfort and availability of bone mass. Nevertheless, it also brings new

\footnotetext{
${ }^{1}$ IsoTis, Bilthoven, The Netherlands.

${ }^{2}$ BMTI and Department of Polymer Chemistry and Biomaterials, University of Twente, Enschede, The Netherlands.

${ }^{3}$ Novamont, Novara, Italy.

${ }^{4}$ Department of Polymer Engineering, University of Minho, Guimarães, Portugal.
} 
drawbacks mainly due to the lack of reproducible osteoinduction and the possibility of immune responses and disease transmission. ${ }^{2}$ With regard to synthetic biomaterials, their success in reconstructing large bone defects is limited because they lack osteoinductive properties that are essential to induce a fast and complete regenerative process. More recently, the development of functional bone tissue equivalents has been widely investigated through bone tissue-engineering strategies. ${ }^{3-7}$ One of these approaches involves the use of patients' own cultured osteogenic cells in combination with an appropriate biomaterial scaffold.

In 1988 Maniatopoulos et al. $^{8}$ cultured rat bone marrow cells from the femora of rats, in the presence of the osteogenic differentiation factor dexamethasone, and reported that these cells differentiated along the osteoblastic lineage and formed bonelike tissue in vitro. Since then, many investigators have described the culture expansion of bone marrow cells from human and several animal species. ${ }^{5,9-22}$ Those studies have demonstrated the ability of the bone marrow cell population to form a bonelike tissue in vitro and/or to induce the formation of bone when implanted ectopically in combination with a suitable biomaterial scaffold.

Bone formation by osteogenic cells is characterized by sequential events involving cell proliferation, expression of osteoblastic markers; and synthesis, deposition, and mineralization of a collagenous matrix. ${ }^{23}$ These events are, however, greatly affected by the type of scaffold material in which the cells were seeded and/or cultured. ${ }^{12-13,24-26}$ The scaffold material should, therefore, allow attachment, growth, and differentiation of osteoprogenitor cells. It should also have high porosity and interconnectivity between pores to facilitate the ingrowth of vascular tissue that will ensure the ultimate survival of the transplanted cells and/or tissue. Ideally, the scaffold material would be easily processed into the desired three-dimensional shape and it would biodegrade after bone tissue formation, resulting in totally natural regenerated tissue. Depending on the type of bone defect (load bearing versus nonload bearing), the material should also provide the mechanical support required.

Graft materials composed of synthetic biodegradable polymeric systems are excellent candidates as substrates for a cell therapy approach in the treatment of bone defects. These materials can be produced with high porosity in complex three-dimensional shapes. Their degradation and mechanical properties can be easily tailored by adjusting the composition and molecular weight of the polymers. To date, several synthetic biodegradable polymers have been evaluated as scaffolds for bone tissue engineering. The most widely investigated polymers are biodegradable poly $(\alpha$-hydroxy esters), such as poly(Llactic acid) (PLLA), ${ }^{24,27}$ poly(glycolic acid) (PGA), ${ }^{28}$ and poly(DL-lactic-co-glycolic acid) (PLGA). ${ }^{14,16,26,29-31}$
Scaffolds made of PLGA with polycaprolactone ${ }^{26,32}$ as well as polycaprolactone alone, ${ }^{26,33-34}$ have also been the subject of studies. Other polymeric systems that have been investigated include poly(propylene fumarate) ${ }^{22}$ and polyurethanes. ${ }^{35}$

With regard to the systems based in poly $(\alpha$-hydroxy esters), reports have demonstrated that these materials support attachment, proliferation, and differentiation of osteogenic cells, ${ }^{24,29}$ as well as the deposition of a bonelike extracellular matrix and its mineralization. ${ }^{16,22,26,29}$ Osteogenic cells cultured in these types of scaffolds were found to form bone tissue when implanted ectopically. ${ }^{14,31}$ Polycaprolactone polymers without blending with PLGA were found to support bone marrow cell growth but not differentiation, ${ }^{26}$ whereas systems based on poly(propylene fumarate) were reported as suitable substrates with respect to attachment, proliferation, and differentiation of these cells. ${ }^{22}$ Despite the promising results obtained with the new polymeric systems, it is difficult to find reports in which the results obtained are related to findings with calcium phosphates, because those materials are widely reported to allow bone marrow cell attachment, growth, differentiation, and bone tissue formation. . $^{9-13,15,17,18-21}$

The aim of the present study was to evaluate two biodegradable polymeric systems as novel substrates for osteoprogenitor cell attachment, growth, differentiation, and bone tissue formation. One of the systems has already been approved for human clinical use ${ }^{36}$ and it consists of a block copolymer composed by poly(ethylene glycol)-terephthalate and poly(butylene terephthalate) (PEGT/PBT), with bone-bonding properties widely reported. ${ }^{37,38}$ The second polymeric system evaluated is composed of corn starch blended with poly $(\varepsilon$-caprolactone) (SPCL).

\section{MATERIALS AND METHODS}

\section{PEGT/PBT copolymer}

Poly(ethylene glycol)-terephthalate/poly(butylene terephthalate) (PEGT/PBT) was prepared at IsoTis NV (Bilthoven, The Netherlands). The copolymer had a PEGT/PBT weight ratio of 70:30 with a PEG molecular weight of $1000 \mathrm{~g} / \mathrm{mol}$. Porous PEGT/PBT blocks were fabricated by a salt leaching method using sodium chloride $(\mathrm{NaCl})$ as the leachable component. $\mathrm{NaCl}$ was sieved into particles ranging from 400 to $600 \mu \mathrm{m}$ in diameter and combined with PEGT/PBT (70:30) granules ground into powder. The mixture was compression molded and, after cooling, the salt was dissolved in water. Both thermal gravitational analysis (TGA) and scanning electron microscopy-electron dispersion X-rays (SEM-EDX) were used to ensure that all the salt was leached from the scaffolds. The porous blocks were then cut into $3 \times 3 \times 2$ 
$\mathrm{mm}$ samples. The intrinsic viscosity of the copolymer was between 0.65 and $0.89 \mathrm{dL} / \mathrm{g}$ and the porosity of the blocks, before testing and under dry conditions, was $75 \%$ in volume. To improve cell attachment and proliferation on the material surfaces, a $\mathrm{CO}_{2}$ plasma treatment was performed for $30 \mathrm{~min}$, as described previously. ${ }^{39}$ After treatment, the blocks were rinsed in water and sterilized in $70 \%$ ethanol, followed by successive washes in phosphate-buffered saline solution (PBS) to remove ethanol residues.

\section{SPCL blend}

The material, composed of corn starch $(30 \%)$ blended with poly ( $\varepsilon$-caprolactone) (70\%) (SPCL) was obtained from Novamont Spa (Novara, Italy). The fibrous blocks were obtained by spinning, cutting, and sintering of the polymeric blend. Under dry conditions, the material had a porosity of $70 \%$ by volume and the thickness of the fibers was approximately $125 \mu \mathrm{m}$. Before testing, the porous blocks were cut into $3 \times 3 \times 2 \mathrm{~mm}$ samples and sterilized in $70 \%$ ethanol, followed by successive washes in PBS to remove ethanol residues.

\section{HA granules}

Porous granules of hydroxyapatite (HA, IsoTis NV) were used as scaffold material. The processing route included the preparation of the HA slurry and mixing of the slurry with polymethylmethacrylate (PMMA) resin (volume ratio of HA to PMMA, 1:1). After shaping in a mold and polymerization, the mixture was subjected to drying, pyrolyzing (to remove all organic phases), and final sintering $\left(1250^{\circ} \mathrm{C}\right.$ for $\left.8 \mathrm{~h}\right)$ in stages. The porosity of the material was approximately $50 \%$, the interconnected pores had a median diameter of $440 \mu \mathrm{m}$, and the size of the implanted particles was approximately $3 \times 3 \times 2$ $\mathrm{mm}$. The granules were steam sterilized for $20 \mathrm{~min}$ at $121^{\circ} \mathrm{C}$.

\section{Isolation and culture of bone marrow cells}

Bone marrow cells were obtained from the femora of 12 young adult male Wistar rats (250-280 g). The marrow cell preparation procedure was described in a previous report. ${ }^{5}$ Briefly, femora were removed and washed in an antibiotic solution with a concentration 10 times higher than in culture medium. After removal of the epiphyses, the bone marrow cells were flushed out with culture medium (see below). The bone marrow obtained from all the rats was pooled and plated in $80-\mathrm{cm}^{2}$ flasks at a density equivalent to one femur per flask. The cells were cultured at $37^{\circ} \mathrm{C}$ in a humidified atmosphere with $5 \% \mathrm{CO}_{2}$, and the culture medium during the entire experimental period consisted of minimum essential medium ( $\alpha$-MEM, Life Technologies, Rockville, MD) containing $15 \%$ fetal bovine serum (FBS, Life Tech- nologies), antibiotics, $0.2 \mathrm{mM}$ L-ascorbic acid 2-phosphate (AsAP; Life Technologies), $0.01 \mathrm{M} \beta$-glycerophosphate ( $\beta \mathrm{GP}$; Sigma, St. Louis, MO) and $10^{-8} \mathrm{M}$ dexamethasone (Sigma). The culture medium was refreshed after $24 \mathrm{~h}$ and thereafter three times per week. At near confluence, the adherent cells were washed with phosphate-buffered saline solution and enzymatically released by means of a $0.25 \%$ trypsin-EDTA solution (Sigma).

\section{Cell seeding and culture on scaffolds}

Before cell seeding all the materials were placed in $\alpha$ MEM for $24 \mathrm{~h}$ at $37^{\circ} \mathrm{C}$ to allow swelling. First-passage cells were seeded on the three types of scaffold placed on bacteriological-grade plates. Aliquots of $100 \mu \mathrm{L}$ of cell suspension were injected with a pipette tip into each block/granule at a density of 200,000 cells per scaffold. Cells were allowed to attach on the material surface for $4 \mathrm{~h}$, after which time an additional $2 \mathrm{~mL}$ of culture medium was added. Cells were grown up to 7 days in culture medium.

\section{DNA assay}

At 1,3, and 7 days of culture, tissue-engineered constructs (four samples per material and time period) were washed in PBS and digested with proteinase $\mathrm{K}$ solution (Sigma), at $56^{\circ} \mathrm{C}$ for a minimum of $16 \mathrm{~h}$. After digestion the samples were stored below $-15^{\circ} \mathrm{C}$ until required for analysis by a CyQUANT dye method. Heparin (LEO Pharma, Ballerup, Denmark) and ribonuclease A solution (Sigma) were added to the cell homogenate. The mixture was shaken and incubated at $37^{\circ} \mathrm{C}$ for $30 \mathrm{~min}$. Samples (100 $\mu \mathrm{l}$ each) were transferred to a 96-well plate and 100 $\mu \mathrm{L}$ of $2 \times$ Cyquant GRDye (Molecular Probes, Eugene, OR) in PBS was added to each well. The samples were incubated at room temperature in the dark for $15 \mathrm{~min}$. A standard curve was made with a stock solution of DNA (100 $\mu \mathrm{g} / \mathrm{mL}$; Sigma). To measure the samples, an LS-

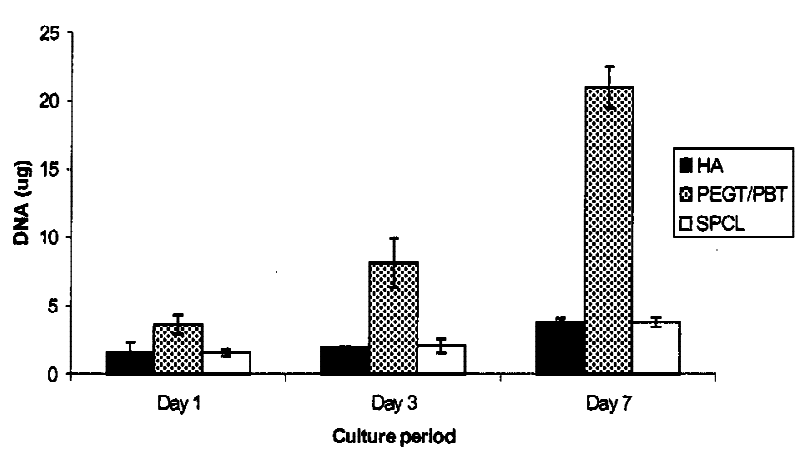

FIG. 1. DNA present on the scaffold constructs after 1, 3, and 7 days of culture. Seeding density: 200,000 cells per scaffold. Scaffold apparent volume: $3 \times 3 \times 2 \mathrm{~mm}$. 
a

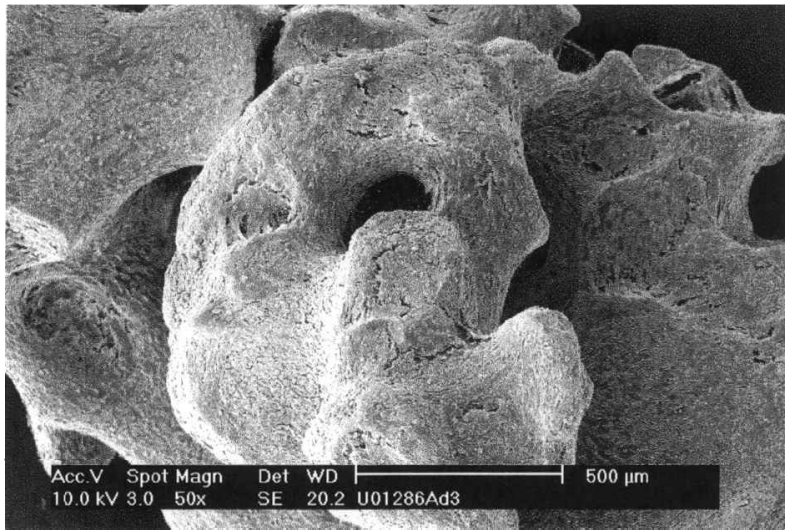

b

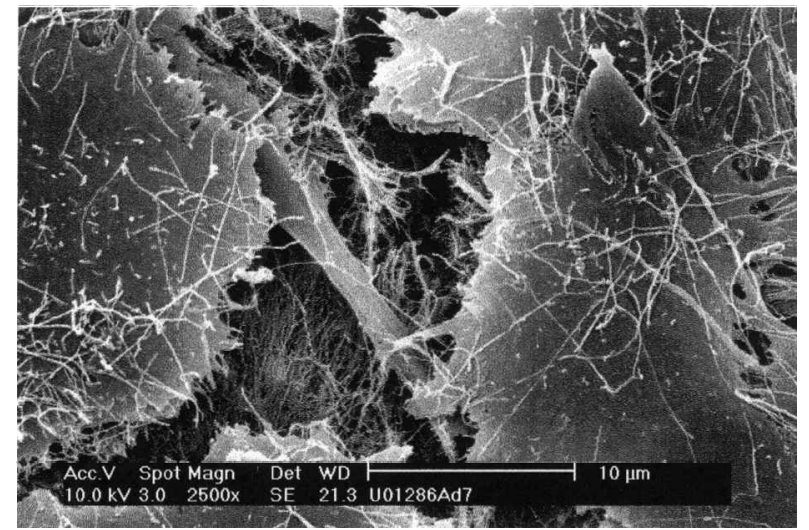

c

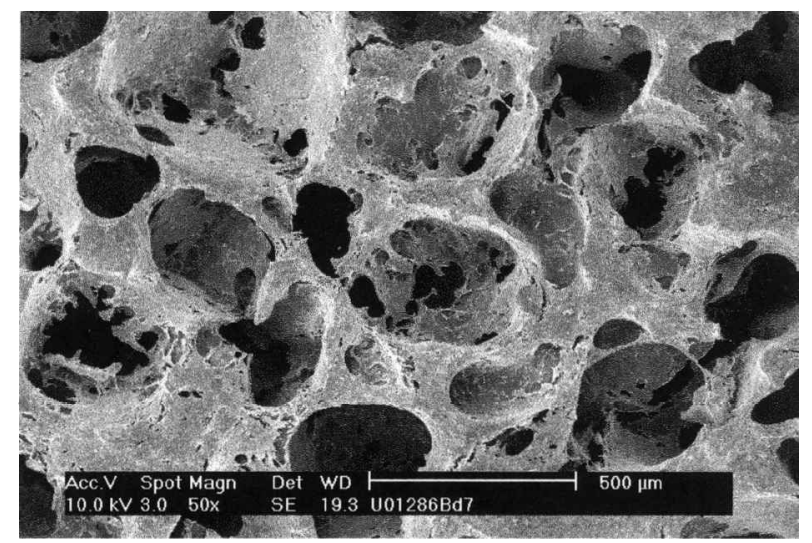

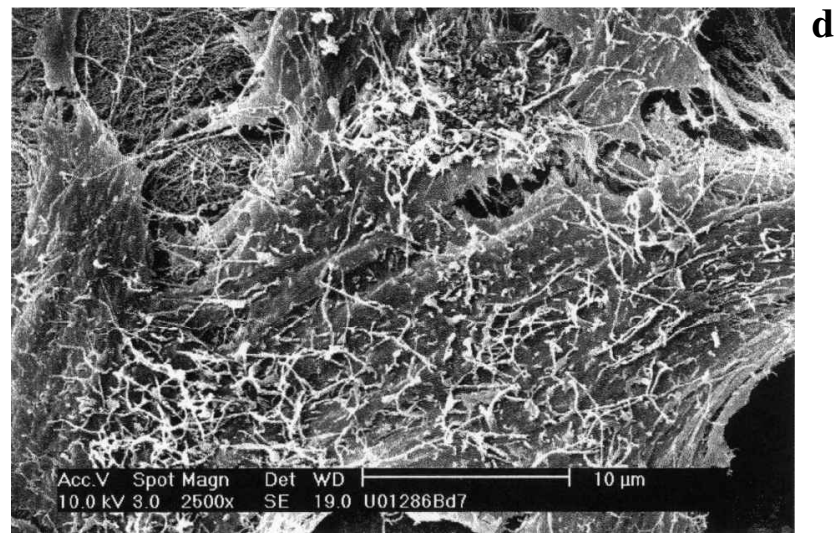
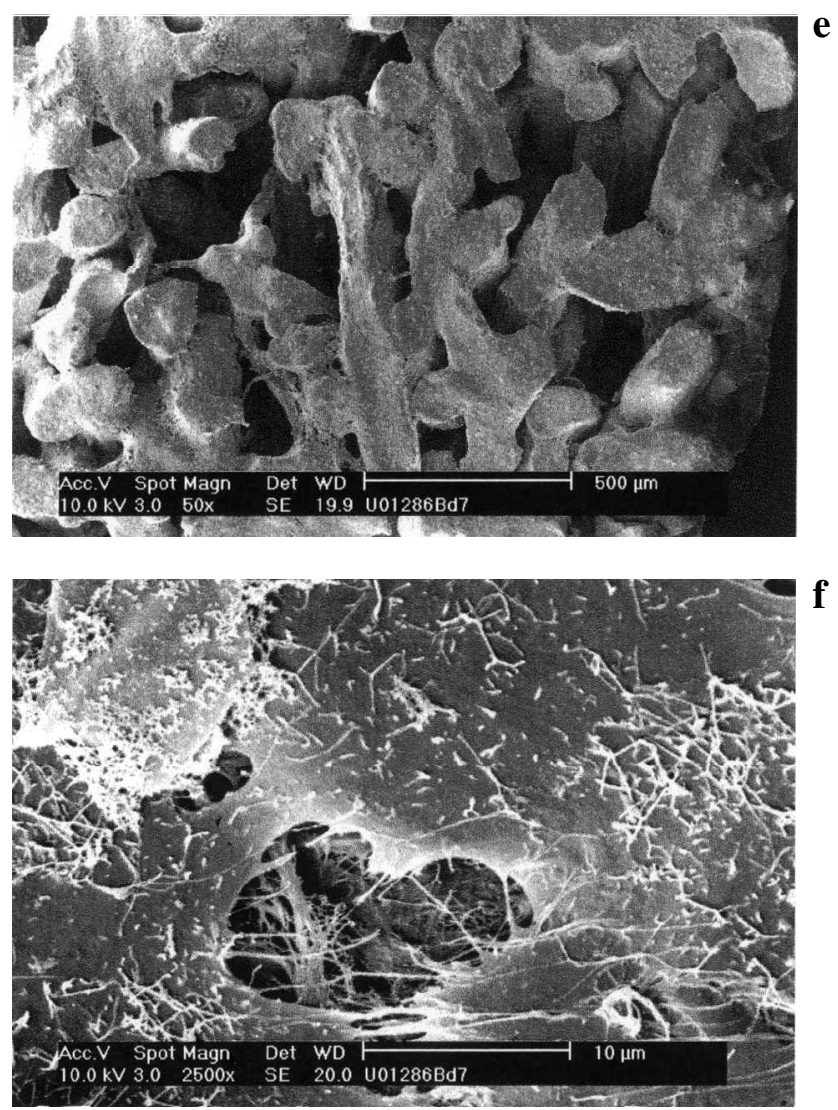

FIG. 2. Scanning electron micrographs of rat bone marrow cells cultured for 7 days on the surface of porous HA (a and $\mathbf{b})$, PEGT/PBT (c and d), and SPCL (e and f) scaffolds. Note the multiple layers of cells, the abundant presence of extracellular matrix, and the numerous collagen-like fibers in between cell layers.

50B with fluorimeter (PerkinElmer, Norwalk, CT) was set with an excitation wavelength at $480 \mathrm{~nm}$ and emission wavelength at $520 \mathrm{~nm}$.

\section{Scanning electron microscopy}

After 1, 3, and 7 days of culture, samples were fixed, dehydrated, critical point dried (Balzers model CPD 030 critical point drier; Bal-Tec, Balzers, Liechtenstein), sputter coated with carbon (Balzers sputter coater model
SCD 004; Bal-Tec), and examined in a Philips (Eindhoven, The Netherlands) XL30 ESEM-FAG scanning electron microscope (three samples per material and per culture period), at an accelerating voltage of $10-15 \mathrm{kV}$.

\section{Alkaline phosphatase staining}

Expression of alkaline phosphatase (ALP) by bone marrow cells cultured on scaffolds was evaluated both after 1 and 7 days of culture (three samples per material and 
time period), using an azo dye method. Briefly, the constructs were fixed for $2 \mathrm{~h}$ in a mixture containing $4 \%$ paraformaldehyde in Sorensen buffer. After washing in demineralized water the samples were incubated for $15 \mathrm{~min}$ in a solution containing naphthol-AS-BI-phosphate (substrate) and Fast Blue RR salt (Sigma). Scaffolds without cells were also incubated in the same solution as controls.

\section{In vivo implantation}

Before implantation, tissue-engineered samples as well as control scaffolds without cells were soaked in serumfree medium and then washed in phosphate-buffered solution prewarmed to $37^{\circ} \mathrm{C}$. Immunodeficient mice (HsdCpb:NMRI-nu) were anesthetized, the surgical sites were cleaned with ethanol, and subcutaneous pockets were created in which samples were inserted. At the end of 4 weeks the samples (eight samples per experimental condition) were removed and fixed in $1.5 \%$ glutaraldehyde in $0.14 \mathrm{M}$ cacodylic acid buffer, $\mathrm{pH}$ 7.3.

\section{Histology}

The fixed samples were dehydrated and embedded in methyl methacrylate. Undecalcified sections were processed with a histological diamond saw (Leica SP1600; Leica Microsystems, Wetzlar, Germany) and stained with $1 \%$ methylene blue solution and $0.3 \%$ basic fuchsin solution in order to visualize bone formation.

\section{Histomorphometry}

To measure material porosity and the amount of bone and bone marrow present in the tissue-engineered implants, as well as the degree of bone contact with the material surface, quantitative measurement was performed with a light microscope coupled to a computerized image analysis system (VIDAS; Kontron, Munich, Germany). The middle section of each implant (eight samples per implant type) was used for this analysis. Measured parameters were defined as follows: porosity, total pore area as compared with total pore and material area; bone formation, total bone area as compared with total pore area; bone marrow formation, total bone marrow area as compared with total pore area; Bone contact, the length of bone in direct contact with the material surface, without the interposition of a fibrous tissue layer, as compared with total material length.

\section{Statistics}

Statistical evaluation was performed by single-factor analysis of variance (ANOVA) to assess statistical significance between the groups of scaffolds. In addition, two-tailed unpaired Student $t$ tests were used to evaluate statistical differences between groups. Statistical significance was defined as $p<0.05$.

\section{RESULTS}

\section{DNA assay}

All scaffold materials supported bone marrow cell attachment and proliferation during the 7 days of in vitro culture, as determined by DNA quantification over time (Fig. 1). Statistical analysis revealed a significant increase in the amount of DNA present on each scaffold over time $(p=0.0003$ for HA, $p<0.0001$ for both PEGT/PBT and SPCL). At all measured time points, PEGT/PBT scaffolds contained a significantly greater number of cells as compared with HA and SPCL, which may be due to the higher surface area of the PEGT/PBT blocks.

\section{Scanning electron microscopy}

On day 1 of culture, scanning electron microscopy examination revealed the presence of isolated cells spread over the material surfaces. In all evaluated scaffolds, the degree of cell-to-cell contact was low. After 3 days in culture, the amount of cells attached to the material surfaces increased, although cells did not cover the entire surface of the scaffolds. On HA constructs, in the higher cell density areas, the first signs of extracellular matrix formation were detected, whereas on the polymeric sam-
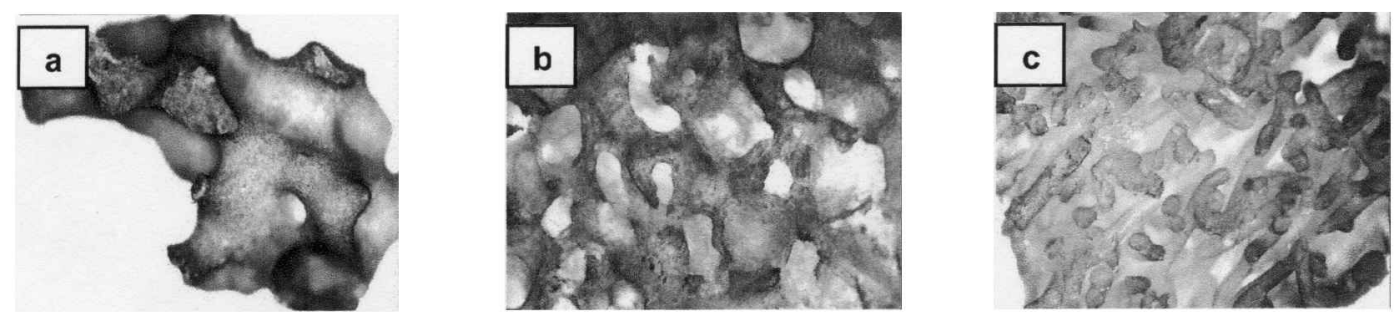

FIG. 3. Light micrographs representing the appearance of rat bone marrow cells stained for ALP activity after 7 days of culture on (a) HA, (b) PEGT/PBT, and (c) SPCL scaffolds. In the azo dye method used, the blue coloration displayed by the cells represents ALP activity. Original magnification, $\times 30$. 
ples cells had not yet visibly started to produce matrix. At the end of 7 days, regardless of the scaffold material, all constructs were covered with multilayers of cells and extracellular matrix (Fig. 2). Abundant collagen-like fibers were detected (Fig. 2b, d, and f), indicating that before implantation the constructs consisted of scaffold material with cultured tissue.

\section{Alkaline phosphatase staining}

The differentiated function of rat bone marrow cells grown on the various material scaffolds was evaluated by monitoring their ALP activity both on day 1 and day 7 . After 1 day of culture, a substantial amount of cells present on both HA and PEGT/PBT constructs stained positive for ALP, as revealed by the blue coloration of the cells. On the SPCL surface, the number of cells positive for ALP was lower as compared with the other scaffolds. With the increase in culture period, the amount of cells expressing this osteoprogenitor cell marker, as well as the intensity of expression, increased, regardless of the scaffold type. On day 7, high ALP activity could be observed in all constructs and, at this time, clear differences between cells cultured on the various scaffolds could not be detected (Fig. 3). Control samples, without cultured cells, did not exhibit any signs of blue coloration on being stained for ALP activity.

\section{Histology}

Regardless of the scaffold material, after 4 weeks of implantation, all implants without cultured cells exhibited fibrovascular tissue invasion into the pore regions without any indication of in vivo osteogenesis. In contrast, in all implants in which bone marrow cells were cultured, consistent and abundant de novo formed bone with extensive areas of bone marrow could be observed (Fig. 4). Bone was distributed over the pore area, penetrating along the entire volume of the scaffolds $(3 \times 3 \times$ $2 \mathrm{~mm}$ ). Moreover, osteogenesis occurred not only in the pores but was also found outside the scaffolds, encapsulating the implants in some areas (Fig. 5). The newly formed bone exhibited a mineralized matrix with lacunae containing osteocytes and osteoblast layers lining the bone surfaces (Fig. 6). In addition, abundant regenerated bone marrow tissue, which contained blood vessels and hematopoietic cells, was detected in all implants (Fig. 6). On the HA implants osteogenesis appeared to start in direct contact with the ceramic surface, without the interposition of a fibrous tissue layer (Fig. 5a). On the polymeric samples, although areas of direct contact were detected, frequently the implants also exhibited islands of bone in the interior of the pores without close contact with the material surfaces (Fig. $5 \mathrm{~b}$ and c). With regard to the presence of other tissue types, despite the intense bone formation observed, cartilaginous tissue and fat tissue were never observed.
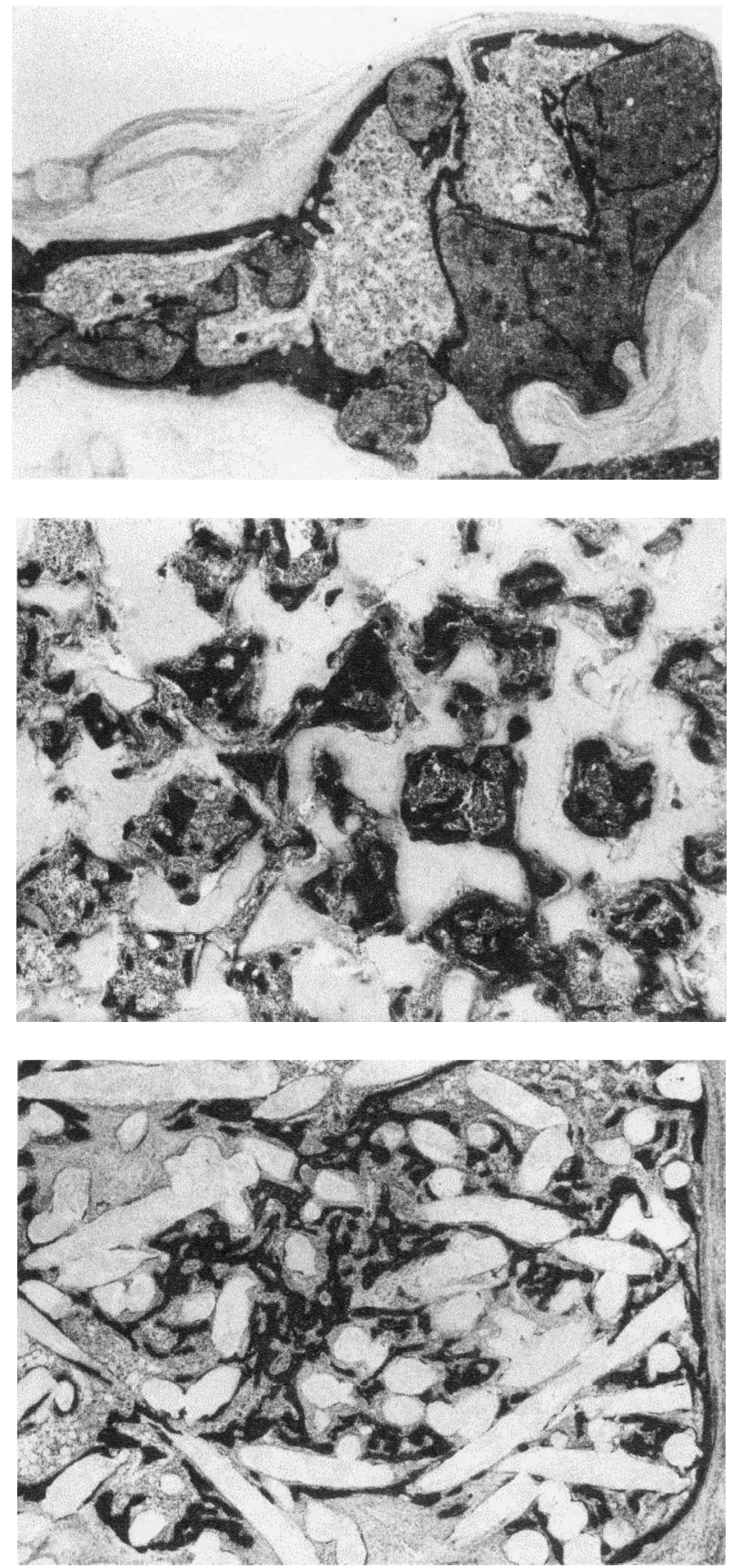

FIG. 4. Light micrographs illustrating representative sections of osteogenesis in (a) HA, (b) PEGT/PBT, and (c) SPCL scaffolds in which rat bone marrow cells were cultured for 7 days before implantation under the skin of nude mice for 4 weeks. Original magnification, $\times 40$.

\section{Histomorphometry}

To evaluate the implants with regard to their porosity, extent of bone and bone marrow formation, as well as the degree of bone contact, histomorphometric analysis was performed on samples harvested at the end of 4 weeks. With respect to porosity, results revealed no significant differences between the three types of scaffold 
a

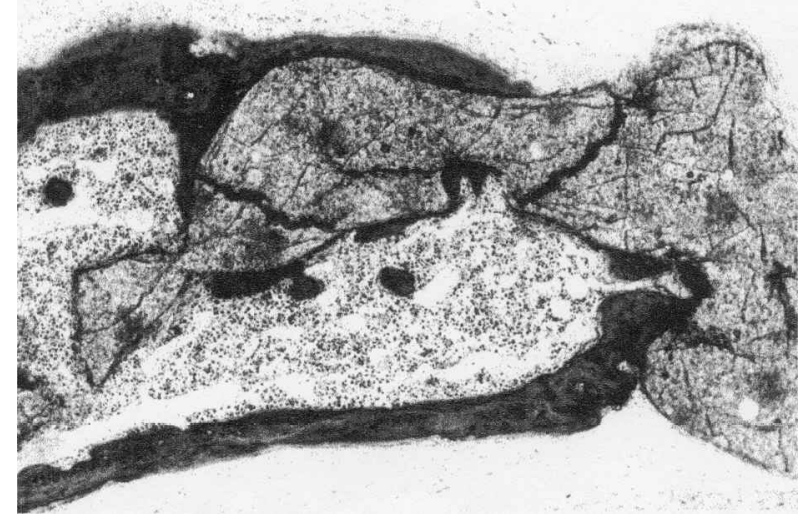

b

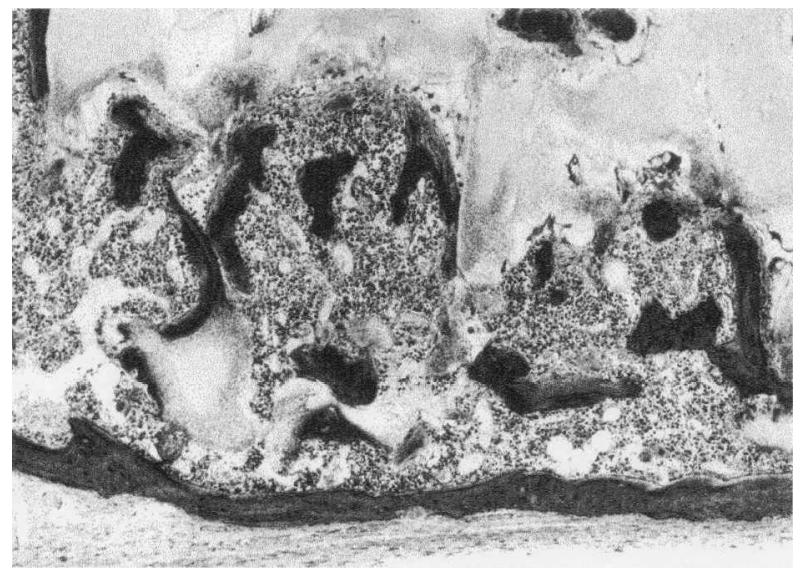

c

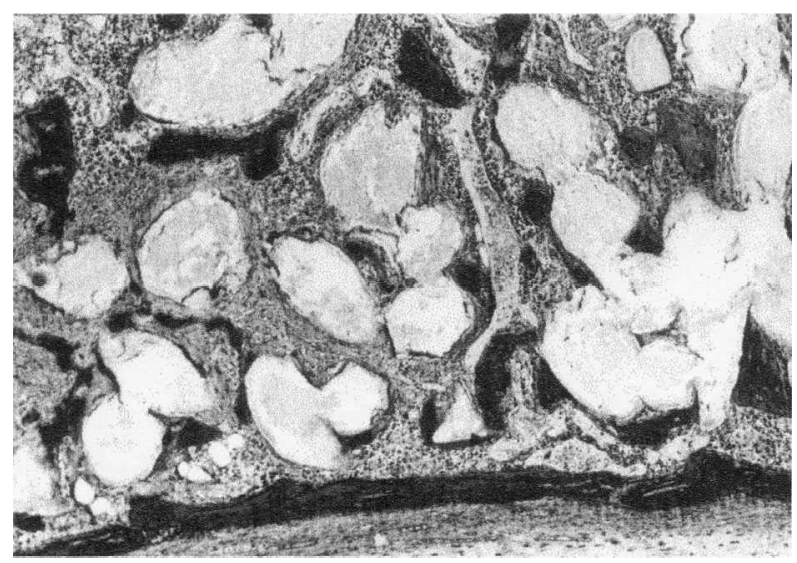

FIG. 5. Light micrographs illustrating areas in which bone was formed outside the pore area of (a) HA, (b) PEGT/PBT, and (c) SPCL implants. Note bone and HA contact and also areas in which bone did not form in direct contact with the polymeric surfaces. Original magnification, $\times 100$.

$(p=0.1025)$. HA presented a porosity level of $48.8 \pm$ $11.3 \%$, whereas the polymeric systems exhibited porosities of $56.6 \pm 4.0$ (PEGT/PBT) and 55.6 \pm 3.4 (SPCL). For both PEGT/PBT and SPCL systems these results indicate a significant decrease in porosity after cell culture and implantation as compared with their porosity before testing (75 and $70 \%$, respectively). The extent of newly formed bone present on the implants is represented in Fig. 7. The degree of osteogenesis, as compared with the available pore area, ranged from $27.7 \pm 9.3 \%$ on HA to $35.5 \pm 10.3$ on PEGT/PBT and $30.1 \pm 2.9$ on SPCL implants. At this time (4 weeks), a significant effect of scaffold material on the extent of bone formation could not be detected $(p=0.2320)$. Nevertheless, the occurrence of bone together with bone marrow was significantly higher on HA constructs as compared with PEGT/PBT and SPCL scaffolds $(p=0.0047$ and $p=0.0056$, respectively). In HA implants the total amount of bone and bone marrow occupied $89.0 \pm 10.0 \%$ of the available pore area, whereas it comprised $62.1 \pm 14.7 \%$ of the void space in PEGT/PBT constructs and filled $62.4 \pm 14.3 \%$ of the pores on SPCL implants (Fig. 8).

With respect to the degree of contact between newly formed bone and scaffold materials (Fig. 9), HA implants presented $63.3 \pm 5.7 \%$ of their surface in direct contact with bone, whereas on polymeric substrates bone contact was substantially lower $(p<0.0001)$, ranging from $22.1 \pm 10.4 \%$ on PEGT/PBT scaffolds to $9.9 \pm 3.9 \%$ in SPCL implants. Moreover, PEGT/PBT implants displayed a statistically higher degree of bone contact as compared with SPCL constructs $(p=0.0121)$. In the PEGT/PBT samples direct microscopic contact with bone was related to the ability of the material to calcify during implantation. Bone contact on these implants was observed exclusively in areas where the material surface presented a calcification layer, whereas on SPCL samples surface calcification was never detected.

\section{DISCUSSION}

The objective of the current investigation was to evaluate two biodegradable polymeric systems as substrates for bone tissue engineering, aiming at non-load-bearing applications. Although the study did not address the biodegradation behavior of the polymers, previous findings by others ${ }^{32,39}$ have proven their degradation capability. In vitro degradation of PEGT/PBT systems is known to occur both by hydrolysis and oxidation, ${ }^{39}$ whereas systems based on poly(caprolactone) are known to degrade by hydrolysis and enzymes. ${ }^{32}$

In the present study, SEM and histological analysis indicated that all the scaffold materials tested possessed a high degree of interconnectivity between the pores. The porosity of both polymeric systems decreased after cell culture and implantation, which is related to the hydrophilic character of the polymers that in contact with fluids will swell, reducing their void space. With regard to cell attachment and proliferation, DNA content and SEM analysis indicated that all scaffolds assessed allowed for bone marrow cell attachment, proliferation, and production of extracellular matrix. With respect to the DNA analysis, PEGT/PBT scaffolds 
$\mathbf{a}$

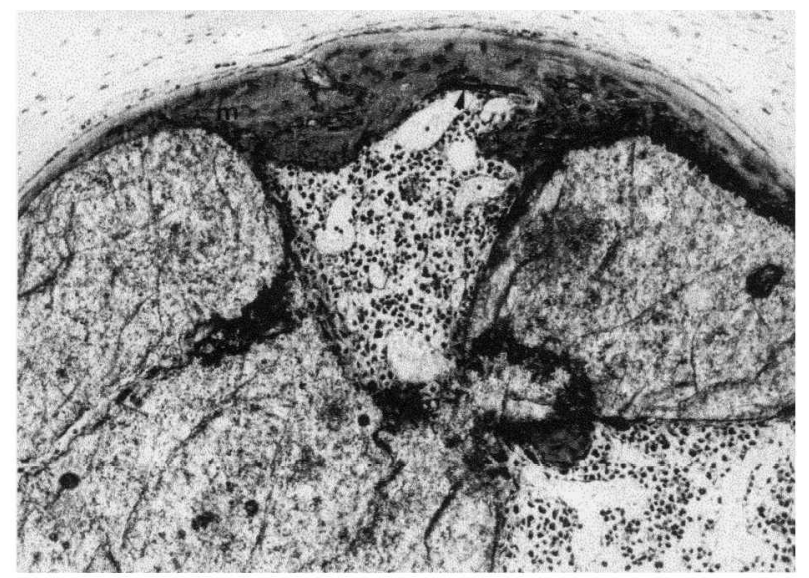

b

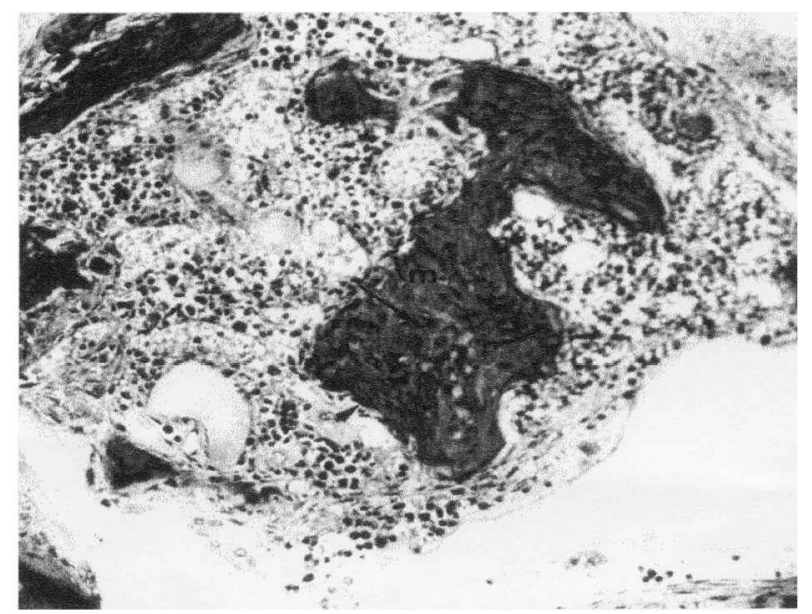

c

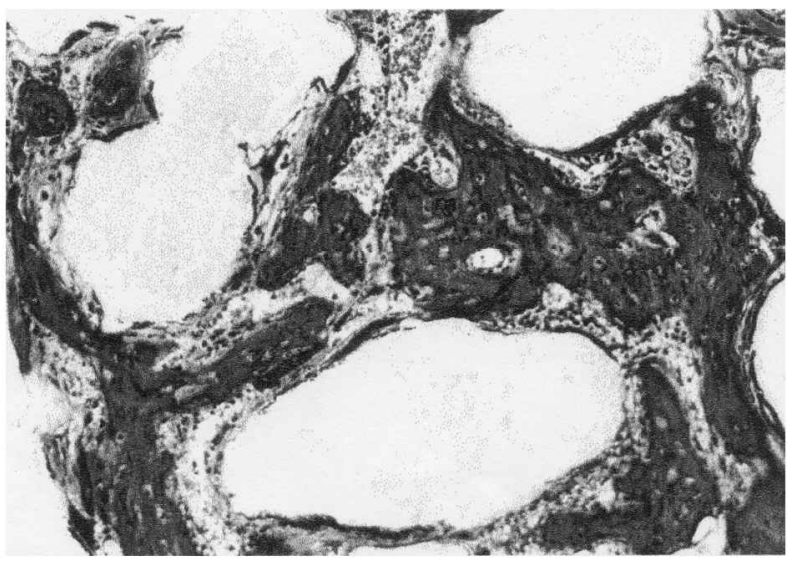

FIG. 6. Light micrographs illustrating the morphology of bone tissue formed on (a) HA, (b) PEGT/PBT, and (c) SPCL implants. Note the mineralized bone matrix (m), with embedded osteocytes (arrow) and layers of osteoblasts (arrowhead). Abundant bone marrow (bm) is also evident. Original magnification, $\times 200$.

contained a substantially higher cell number as compared with HA and SPCL. Because after 7 days of culture all scaffolds were completely covered with cells, this appears to be related to a higher surface area of the PEGT/PBT samples, which allowed for additional cell growth.
As reported by other investigators, ${ }^{16,22,26}$ the ability of osteoprogenitor cells to differentiate along the osteoblastic lineage was assessed by their ALP activity. ALP is widely considered a marker for the osteogenic phenotype.$^{40}$ After 7 days of culture, cells grown on both polymeric scaffolds and on HA stained intensively positive for ALP activity, suggesting that the engineering of hybrid (tissue and material) constructs with osteogenic potential was successful. Using a two-dimensional culture system, Calvert et al. ${ }^{26}$ reported that poly(caprolactone) substrates, although allowing for bone marrow cell growth, inhibit osteogenic differentiation. In our study, the blend of cornstarch and poly( $\varepsilon$-caprolactone) was shown to be a suitable substrate for bone marrow cell proliferation and differentiation. These divergent results can be attributed to both the presence of starch in our system and, more likely, to the different culture conditions used in the studies. In fact, in a study by Hutmacher et al. ${ }^{33}$ it was demonstrated that periosteal cells were able to proliferate, differentiate, and produce extracellular matrix in a three-dimensional poly(caprolactone) matrix.

With regard to the in vivo osteogenic potential of the tissue-engineered constructs, the results demonstrated that bone marrow cells cultured on all scaffolds induced the formation of large quantities of bone tissue that supports hematopoiesis. Moreover, de novo formed bone and bone marrow were distributed over the entire scaffold volume, resulting in a penetration depth of bone tissue of at least $1.0 \mathrm{~mm}$. These findings are relevant because in similar studies Riley et al. ${ }^{14}$ and Ishaug et al.,${ }^{14,16}$ using rat bone marrow cells cultured on PLGA foams, reported a maximum penetration depth of bone of approximately $0.25 \mathrm{~mm}$ after 4 weeks of implantation. The penetration depth of mineralized tissue after 4 weeks of in vitro culture was $0.15 \mathrm{~mm}$. Furthermore, in the present study the amount of bone formation in the polymeric constructs filled more than $30 \%$ of their available pore area, while the extent of bone and bone marrow occupied more than

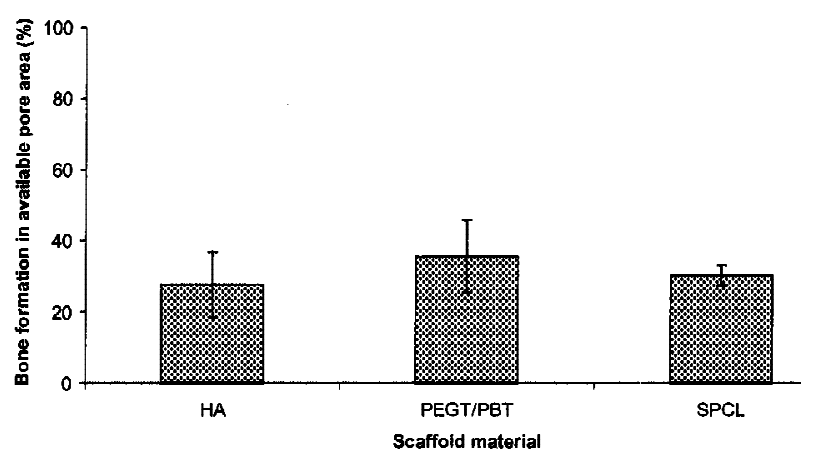

FIG. 7. Extent of bone formation on the tissue-engineered constructs after 4 weeks of implantation. Effect of the material scaffold evaluated on the degree of bone formation was not significant $(p=0.2320)$. 


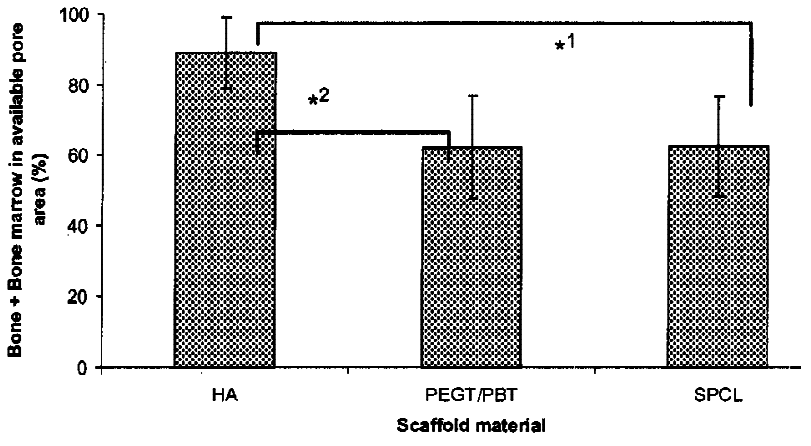

FIG. 8. Extent of bone and bone marrow present on the tissue-engineered constructs after 4 weeks of implantation. *Significant difference was found between HA and the polymeric scaffolds. ${ }^{* 1} p=0.0047 ;{ }^{* 2} p=0.0056$.

$62 \%$ of the pores. Direct comparisons between these investigations and others using different biodegradable polymeric systems ${ }^{14,28,30-35}$ are difficult. This is because of the diverse study set ups. To our knowledge, such a high degree of bone tissue formation by cultured cells after 4 weeks has not yet been reported.

With respect to the histological characterization of the implant, an interesting feature found both on HA and polymeric constructs was the formation of a bone tissue layer at the outside of the implants, which covered their outer surfaces and encapsulated the constructs in some areas. These observations are contradictory to those of Ohgushi et al., ${ }^{9}$ who reported osteogenesis exclusively found in the material pores as a characteristic feature of ectopic bone formation induced by bone marrow cells in calcium phosphate ceramics. In our view, this discrepancy of results may be due to the fact that, in the abovementioned work, cells were seeded on the ceramic materials and directly implanted, whereas in our study cells were cultured on the scaffolds for 1 week before implantation. This procedure allowed cells to form a bonelike tissue layer not only inside but also on the outer surface of the implants. As a result, after implantation, fibrous tissue invasion from the host could be achieved through the center of the pores but it could not completely invade the material's outer surface because an in vitroformed bonelike tissue was already present.

In this study, the process of bone formation comprised osteoprogenitor cell attachment, growth, differentiation, and in vivo deposition of mineralized bone with subsequent remodeling and bone marrow regeneration. The extent of bone present in HA constructs was similar to that observed with the polymeric implants. However, because the amount of bone marrow in HA samples was significantly higher as compared with PEGT/PBT and SPCL implants, the process of osteogenesis seems to have occurred faster with HA constructs.

With regard to the degree of contact between the ma- terials and newly formed bone, in HA and as previously reported ${ }^{9,10}$ bone formation appeared to start at the surface of the material, which resulted in a high degree of bone contact. With the polymeric constructs this contact was substantially lower; for PEGT/PBT implants it was approximately $22 \%$ whereas for SPLC implants it was under $10 \%$. The large difference observed between the two polymeric systems is justified by the formation of a calcification layer at the PEGT/PBT surfaces due to the uptake of fluid containing calcium ions, which confers to the material bone-bonding properties. ${ }^{38}$ In fact, in the present study direct contact between bone and PEGT/ PBT implants was observed only in areas where the material surface was calcified. Comparisons of bone contact results obtained with PEGT/PBT and SPCL systems and other biodegradable polymers could not be performed because of the difficulty in finding reports that addressed the contact between bone induced by osteogenic cells on the implant and the material. Nevertheless, to obtain polymers with a degree of osteoconductivity similar to that of HA, further optimization is required. For the PEGT/PBT samples precalcification of the material before implantation may substantially increase bone contact, whereas for the SPCL system a thin calcium phosphate coating on the material surface may also increase bone contact.

\section{CONCLUSIONS}

Rat bone marrow cells seeded and cultured on porous biodegradable PEGT/PBT and SPCL blocks were able to differentiate, produce extracellular matrix, and induce the abundant formation of bone and bone marrow tissue. In addition, at the implantation period assessed, the extent of newly formed bone on the polymeric constructs was similar to the degree of bone formation on HA implants. These findings indicate that the tested polymers are suit-

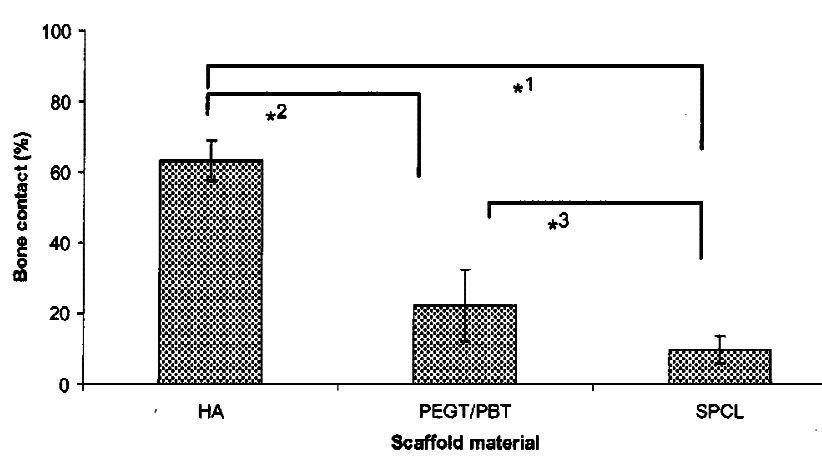

FIG. 9. Degree of contact between newly formed and implant materials at 4 weeks. ${ }^{*}$ Significant difference was found between HA and the polymeric scaffolds and between PEGT/PBT and SPCL implants. ${ }^{* 1} p<0.0001 ;{ }^{2} p<0.0001 ; *^{3} p=0.0121$. 
able scaffolds for a bone tissue-engineering approach in the treatment of bone defects. Nevertheless, because the degree of bone contact was higher on HA scaffolds, the osteoconductive properties of the polymeric systems will need to be further modulated.

\section{ACKNOWLEDGMENTS}

The authors acknowledge the European Community Brite-Euram project BE97-4612 and the Dutch Department of Economic Affairs for financially supporting part of this study. In addition, the authors are grateful to Robert Haan, Marjan Sleijster, and Patrick Engelberts (IsoTis NV) for production of the PEGT/PBT materials and for technical support.

\section{REFERENCES}

1. Damien, C., and Parsons, R. Bone graft and bone graft substitutes: A review of the current technology and applications. J. Appl. Biomater. 2, 187, 1991.

2. de Boer, H.H. The history of bone grafts. Clin. Orthop. 226, 292, 1988.

3. Yaszemski, M.J., Payne, R.G., Hayes, W.C., Langer, R., and Mikos, A.G. Evolution of bone transplantation: Molecular, cellular and tissue strategies to engineer human bone. Biomaterials 17, 175, 1996.

4. Langer, R. Tissue engineering: A new field and its challenges. Pharm. Res. 14, 840, 1997.

5. de Bruijn, J., van den Brink, I., Mendes, S., Dekker, R., Bovell, Y.P., and van Blitterswijk, C.A. Bone induction by implants coated with cultured osteogenic bone marrow cells. Adv. Dent. Res. 13, 74, 1999.

6. Laurencin, C.T., Attawia, M., and Borden, M.D. Advancements in tissue engineered bone substitutes. Curr. Opin. Orthop. 10, 445, 1999.

7. Oreffo, R.O.C., and Triffitt, J.T. Future potentials for using osteogenic stem cells and biomaterials in orthopedics. Bone 25, 5S, 1999.

8. Maniatopoulos, C., and Sodek, J. Melcher AH. Bone formation in vitro by stromal cells obtained from bone marrow of young adult rats. Cell Tissue Res. 254, 317, 1988.

9. Ohgushi, H., Okumura, M., Tamai, S., Shors, E., and Caplan, A.I. Marrow cell induced osteogenesis in porous hydroxyapatite and tricalcium phosphate: A comparative histomorphometric study of ectopic bone formation. J. Biomed. Mater. Res. 24, 1563, 1990.

10. Ohgushi, H., and Okumura, M. Osteogenic capacity of rat and human marrow cells in porous ceramics. Acta Orthop. Scand. 61, 431, 1990.

11. Yoshikawa, T., Ohgushi, H., and Tamai S. Immediate bone forming capability of prefabricated osteogenic hydroxyapatite. J. Biomed. Mater. Res. 32, 481, 1996.

12. Kuznetsov, S.A., Krebsbach, P.H., Satomura, K., Kerr, J., Riminucci, M., Benayahu, D., and Robey, P.G. Singlecolony derived strains of human marrow stroma fibroblasts form bone after transplantationin vivo. J. Bone Miner. Res. 12, 1335, 1997.

13. Krebsbach,P.H., Kuznetsov, S.A., Satomura, K., Emmons, R.V.B., Rowe, D.W., and Robey, P.G. Bone formation in vivo: Comparison of osteogenesis by transplanted mouse and human marrow stromal fibroblasts. Transplantation 63, 1059, 1997.

14. Riley, S.L.I., Crane, M.G., Gurlek, A., Miller, M.J., Yasko, A.W., Yaszemski, M.J., and Mikos, A.G. Ectopic bone formation by marrow stromal osteoblast transplantation using poly(DL-lactic-co-glycolic acid) foams implanted into the rat mesentery. J. Biomed. Mater. Res. 36, 1, 1997.

15. Yoshikawa, T., Ohgushi, H., Dohi, Y., and Davies, J.E. Viable bone formation in porous hydroxyapatite: Marrow cell-derived in vitro bone on the surface of ceramics. Biomed. Mater. Eng. 7, 49, 1997.

16. Ishaug, S.L., Crane, M., Miller, M.J., Yasko, A.W., Yaszemski, M.J., and Mikos, A.G. Bone formation by three-dimensional stromal osteoblast culture in biodegradable polymer scaffolds. J. Biomed. Mater. Res. 36, 17, 1997.

17. Mendes, S.C., van den Brink, I., de Bruijn, J.D., and van Blitterswijk, C.A. In vivo bone formation by human bone marrow cells: Effect of osteogenic culture supplements and cell densities. J. Mater. Sci. Mater. Med. 9, 855, 1998.

18. Yoshikawa, T., Ohgushi, H., Uemura, T., Nakajima, H., Ichijima, K., Tamai, S., and Tateisi, T. Human bone marrow cells-derived cultured bone in porous ceramics. Biomed. Mater. Eng. 8, 311, 1998.

19. Mendes, S.C., de Bruijn, J.D., Bakker, K., Apeldoorn, A.A., Platenburg, P.P., Tibbe, G.J.M., and van Blitterswijk, C.A. Human bone marrow stromal cells for bone tissue engineering: In vitro and in vivo characterisation. In: Davies, J.E., ed. Bone Engineering. Toronto, ON, Canada: Em Square, 2000, pp. 505-515.

20. Anselme, K., Noel, B., Flautre, B., Blary, M.C., Delecourt, C., Descamps, M., and Hardouin, P. Association of porous hydroxyapatite and bone marrow cells for bone regeneration. Bone 25, 51S, 1999.

21. Yoshikawa, T., Ohgushi, H., Uemura, T., Nakajima, H., Yamada, E., Ichijima, K., Tamai, S., and Ohta, T. In vivo osteogenic durability of cultured bone in porous ceramics. Transplantation 69, 128, 2000.

22. Peter, S.J., Lu, L., Kim, D.J., and Mikos, A.G. Marrow stromal osteoblast function on a poly(propylene fumarate) $/ \beta$-tricalcium phosphate biodegradable orthopaedic composite. Biomaterials 21, 1207, 2000.

23. Aubin, J.E., and Liu, F. The osteoblast lineage. In: Bilizekian, J., and Rodan, G., eds. Principles of Bone Biology. San Diego, CA: Academic Press, 1996, pp. 39-50.

24. Göpferich, A., Peter, S.J., Lucke, A., Lu, L., and Mikos, A.G. Modulation of marrow stromal cell function using poly(D,L-lactic acid)-block-poly(ethyleneglycol)-monomethyl ether surfaces. J. Biomed. Mater. Res. 46, 390, 1999.

25. Mendes, S.C., de Bruijn, J.D., Huipin, Y., and van Blitterswijk, C.A. Evaluation of a porous hydroxyapatitetricalcium phosphate ceramic as a scaffold material for bone tissue engineering. Abstract presented at the 6th World Biomaterials Congress, Kamuela, Hawaii, 2000. Abstract no. 454 . 
26. Calvert, J.W., Marra, K.G., Cook, L., Kumta, P.N., DiMila, P.A., and Weiss, L.E. Characterization of osteoblastlike behavior of cultured bone marrow stromal cells on various polymer surfaces. J. Biomed. Mater. Res. 52, 279, 2000.

27. Winn, S.R., Schmit, J.M., Buck, D., Hu, Y., Grainger, D., and Hollinger, J.O. Tissue-engineered bone biomimmetic to regenerate calvarial critical-sized defects in athymic rats. J. Biomed. Mater. Res. 45, 414, 1999.

28. Breitbart, A.S., Grande, D.A., Kessler, R., Ryaby, J.T., Fitzsimmons, R.J., and Grant, R.T. Tissue engineered bone repair of calvarial defects using cultured periosteal cells. Plast. Reconstr. Surg. 101, 567, 1998.

29. Riley, S.L.I., Kruger, G.M.C., Yaszemski, M.J., and Mikos, A. Three-dimensional culture of rat calvarial osteoblasts in porous biodegradable polymers. Biomaterials 19, 1405, 1998.

30. Perka, C., Schultz, O., Spitzer, R.S., Lindenhayn, K., Burmester, G.R., and Sittinger, M. Segmental bone repair by tissue-engineered periosteal cell transplants with bioresorbable fleece and fibrin scaffolds in rabbits. Biomaterials 21, 1145, 2000.

31. Weng, Y., Cao, Y., Silva, C.A., Vacanti, M.P., and Vacanti, C.A. Tissue engineered composites of bone and cartilage for mandible condylar reconstruction. J. Oral Maxillofac. Surg. 59, 185, 2001.

32. Marra, K.G., Szem, J.W., DiMilla, P.A., and Weiss, L.E. In vitro analysis of biodegradable polymer blend/hydroxyapatite composites for bone tissue engineering. J. Biomed. Mater. Res. 47, 324, 1999.

33. Hutmacher, D.W., Schantz, T., Zein, I., Ng, K.W., Teoh, S.H., and Tan, K.C. Mechanical properties and cell cultural response of polycaprolactone scaffolds designed and fabricated via fused deposition modeling. J. Biomed. Mater. Res. 55, 203, 2001.

34. Ng, K.W., Hutmacher, D.W., Schantz, T., Ng, C.S., Too, H.P., Lim, T.C., Phan, T.T., and Teoh, S.H. Evaluation of ultra-thin poly( $\varepsilon$-caprolactone $)$ films for tissue-engineered skin. Tissue Eng. 7, 441, 2001.

35. Saad, B., Ciardelli, G., Matter, S., Welti, M., Uhlshmid, G.K., Neuenschwander, P., and Suter, U.W. Degradable and highly porous polyesterurethane foam as biomaterial: Effects and phagocytosis of degradation products in osteoblasts. J. Biomed. Mater. Res. 39, 594, 1998.

36. Bulstra, S.K., Geesink, R.G. Bakker, D., Bulstra, T.H., Bouwmeester, S.J., and van der Linden, A.J. Femoral canal occlusion in total hip replacement using resorbable and flexible cement restrictor. J. Bone Joint Surg. Br. 78, 892, 1996.

37. Bakker, D., van Blitterswijk, C.A., Hesseling, S.C., Daems, W.T., and Grote, J.J. Tissue/biomaterial interface characteristics of four elastomers. A transmission electron microscopical study. J. Biomed. Mater. Res. 24, 277, 1990.

38. Radder, A.M., Leenders, H., and van Blitterswijk, C.A. Interface reactions to PEO/PBT copolymers (Polyactive) after implantation in cortical bone. J. Biomed. Mater. Res. 28, 141, 1994.

39. Deschamps, A.A., Claase, M.B., Sleijster, W.J., de Bruijn, J.D., Grijpma, D.W., and Feijen, J. Design of segmental poly(ether ester) materials and structures for the tissue engineering of bone. Journal of Control. Release 78, 175, 2002.

40. Bruder, S.P., Horowitz, M.C., and Mosca, J.D. Haynesworth SE. Monoclonal antibodies reactive with human osteogenic cell surface antigens. Bone 21, 225, 1997.

Address reprint requests to: J.D. de Bruijn, B.Sc., Ph.D. IsoTis $N V$ P.O. Box 98 3720 MB Bilthoven, The Netherlands

E-mail: joost.de.bruijn@isotis.com 